\title{
Outlandish presentation of a steroid cell tumor - distinct by its bilaterality and distant spread
}

\author{
Moulima Banerjee*, Sanghamitra Mukherjee, Manisha Mahata, Gopinath Barui
}

Department of Pathology, R G Kar Medical College, Kolkata-700004, West Bengal, India

Received: 06 March 2016

Accepted: 04 April 2016

\section{*Correspondence:}

Dr. Moulima Banerjee,

E-mail: moulimabanerjee16@gmail.com

Copyright: (c) the author(s), publisher and licensee Medip Academy. This is an open-access article distributed under the terms of the Creative Commons Attribution Non-Commercial License, which permits unrestricted non-commercial use, distribution, and reproduction in any medium, provided the original work is properly cited.

\section{ABSTRACT}

Steroid cell tumors of ovary constitute an uncommon group of ovarian neoplasms composed of large cells with intracellular lipid that resemble leydig cells or luteinized stromal cells. They are characterized by their clinical manifestations which are reflections of the underlying hormonal disturbances. This case report is of a $22 \mathrm{yrs}$ old female with an abdominal mass whose presenting symptom was just amenorrhea for 9 months. However the final diagnosis after excision of the mass and histopathological examination left the unsuspecting physicians in surprise.

Keywords: Ovarian tumor, Steroid cell tumor-NOS, Bilateral, Malignant

\section{INTRODUCTION}

Ovarian tumors can be classified into a wide variety of benign and malignant tumors with surface epithelial and germ cell tumors dominating the picture. Steroid cell tumors fall under the category of pure Stromal tumors and account for less than $0.1 \%$ of all ovarian neoplasms. ${ }^{1}$ The origin and pathogenesis of these tumors are still under much controversy. The tumors cells resemble steroid secreting cells of adrenal cortex hence the nomenclature. ${ }^{2,3}$ Bilateral tumors amount to only $6 \%$ out of total number of steroid cell tumors reported so far. ${ }^{4}$

\section{CASE REPORT}

A 22yrs old unmarried woman presented in the emergency with severe lower abdominal pain and vomiting for 2 days. She also gave history of amenorrhoea for 9 months. On physical examination the woman was thin built and short in height with progressive atrophy of breasts. Per abdominal examination revealed a large mass in the lower abdomen reaching up to umbilicus.

USG of lower abdomen was done and a well-defined solid heterogeneous lesion was seen in the right adenexa measuring $9.8 \times 9.7 \mathrm{cms}$. No cystic area seen. Another almost similar lesion in left adenexa seen measuring $6.6 \times 4.2 \mathrm{cms}$. Ovaries could not be delineated separately. Left sided hydronephrosis also seen.

CECT whole abdomen revealed a large strongly enhancing pelvic mass $100 \times 100 \times 92 \mathrm{~mm}$ with its mass effect causing left sided hydronephrosis and compressing and adherent with adjacent gut loops and urinary bladder. Possibility of ovarian tumor was considered. Also periportal and peripancreatic lymphadenopathy and metastasis in right lobe of liver was seen.

Biochemical parameters were done. Serum AFP was $>3000 \mathrm{ng} / \mathrm{ml}$ (elevated), CA-125 was 191.5 (elevated) and CEA was 1.34 (normal). Hormonal levels were not assessed as Stromal tumor was not suspected due to absence of clinical features.

The patient was operated next. Abdomen was opened with midline incision and a large $15 \times 15 \mathrm{cms}$, irregular, haemorrhagic, lobulated mass adherent with omentum was seen. Another $10 \times 10 \mathrm{cms}$ lobulated mass in right hypochondrium seen adherent to stomach, liver and pancreas. Pelvic mass was removed by infracolic omentectomy but right hypochondriac mass could not be 
dissected out due to bleeding from liver metastatic sites. Abdomen was closed after controlling the bleeding.

Specimen labelled as ovary sent to the pathology department measured $19 \times 12 \times 10 \mathrm{cms}$. Outer surface was lobulated and focally haemorrhagic. On cut section the mass was solid and greyish yellow in colour. On microscopic examination section from tumor showed large round to polygonal cells with granular eosinophilic cytoplasm with fine vacuolation in some, separated by fibrous septa. Tumor cells had distinct cell membrane and central nuclei and often prominent nucleoli. Areas of necrosis and haemorrhage noted. No Reinke's crystal found. From overall histopathological features a diagnosis of Steroid cell tumor-not otherwise specified was given.

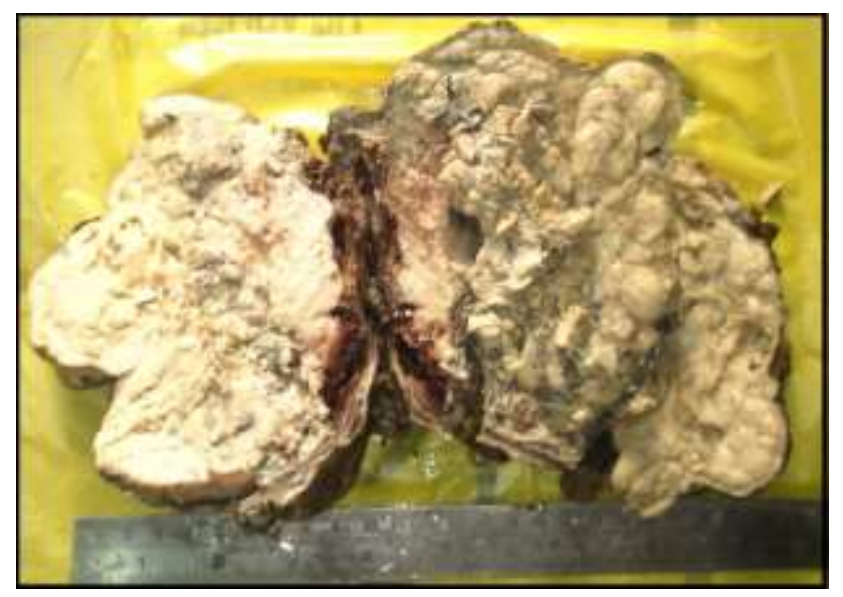

Figure 1: Gross picture of the large lobulated mass $(15 \times 12 \times 10) \mathrm{cms}$ with cut section showing solid areas with haemorrhagic spots.

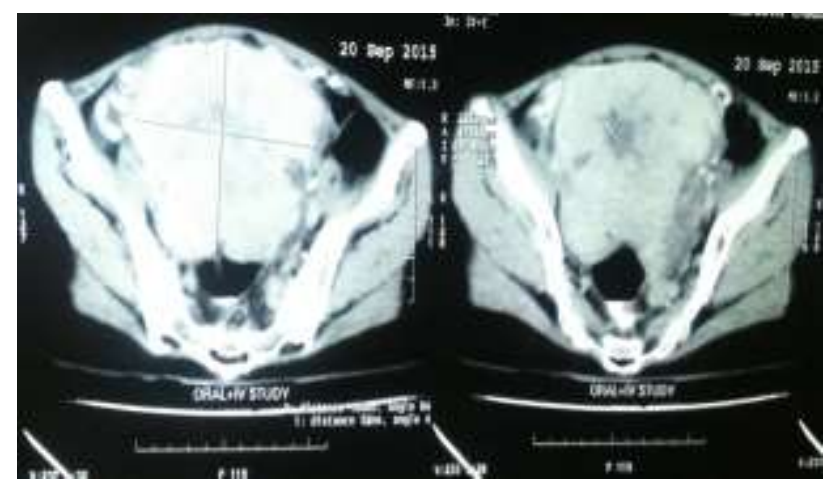

Figure 2: CT scan showing a large $(100 \times 100 \times 92) \mathrm{mm}$ strongly enhancing SOL in pelvis.

\section{DISCUSSION}

Steroid cell tumors account for less than $0.1 \%$ of ovarian neoplasms. It is subdivided into three subtypes as per cell of origin:

1. Stromal luteomas arising from ovarian stroma.

2. Leydig cell tumors arising from leydig cells in the hilus.
3. Steroid cell tumor-NOS when lineage of the tumor is not identified. ${ }^{5}$ About $60-80 \%$ falls in the NOS category. ${ }^{5}$

These tumors can occur in any age (mean age around 43 years). ${ }^{1}$ About half the patients present with androgenic symptoms, $10 \%$ with estrogenic symptoms and less than one-fourth present without any hormonal disturbances. ${ }^{1,4}$

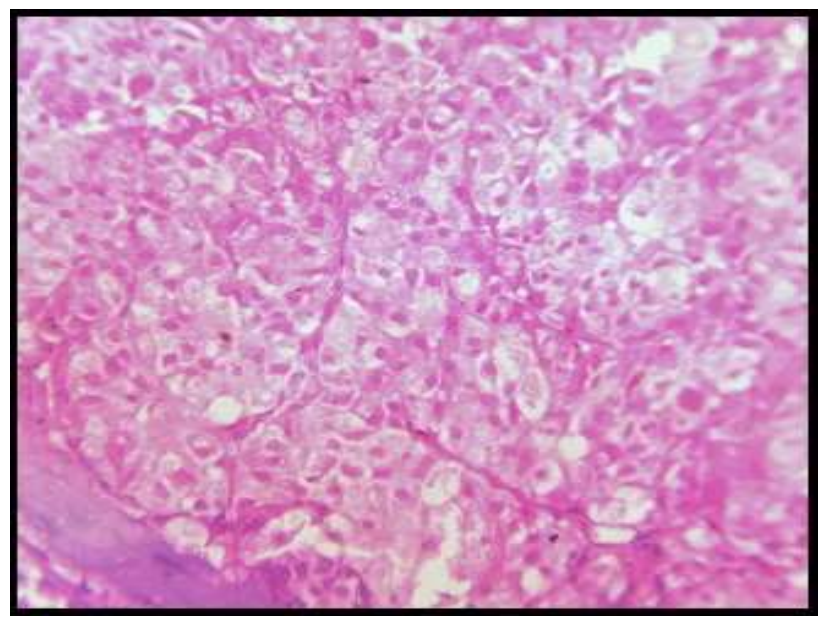

Figure 3: Microscopic picture showing lobules of large round to polygonal cells with granular eosinophilic cytoplasm with vacuolation separated by fibrous septa.

The clinical symptoms in these cases are due to underlying hormonal disturbances. Features of masculinizatiom usually develop through two definite phases- an early defeminization phase which presents as oligomenorrhoea or amenorrhoea followed by common signs of masculinisation like hirsutism, clitoral enlargement, enlargement of larynx, deepening of voice and temporal alopecia. ${ }^{5}$

Our case presented at a young age of $22 \mathrm{yrs}$ with complaints of amenorrhoea for few months only. She had no previous complaints and no signs of virilisation.

The most important feature of a tumor is to determine whether it is benign or malignant. Hayes and Scully gave us some features that are highly indicative of malignancy in steroid cell tumors. ${ }^{3}$ These features are- tumor diameter $>7 \mathrm{cms}$, mitotic figures per 10 high power field $>=2$, necrosis, haemorrhage and grade 2-3 nuclear atypia. ${ }^{3,5}$ Our case had all these features and in addition metastatic deposit in liver was seen in CECT.

The mainstay of treatment of any ovarian tumor is surgery. ${ }^{5}$ In small tumors or women with stage 1 disease unilateral oophorectomy is done in patients whose family is not yet completed. For elderly patients total hysterectomy with bilateral salpingo oophorectomy is advised. ${ }^{5}$ Adjuvant chemotherapy is advocated however no clear-cut guidelines have been established. Our patient had large bilateral tumor with adhesion to adjacent organs 
and omentum and features of hydronephrosis due to mass effect. During surgery due to bleeding from liver metastasis patient's condition deteriorated therefore only left side tumor could be dissected out. The patient is on chemotherapy presently awaiting for physical conditions to improve so that the right side mass could also be operated.

\section{CONCLUSION}

This case stands out as intriguing not only because of the rarity of its incidence but also due to the unique way it presented. Such large bilateral malignant tumors presented only with amenorrhoea for few months and few nonspecific symptoms. Signs of virilisation which is almost quintessential for this tumor was absent here.

Funding: No funding sources Conflict of interest: None declared

Ethical approval: Not required

\section{REFERENCES}

1. WHO classification of tumors of female reproductive organs. Edited by Kurman RJ, Carcangiu ML, Young RH. Fourth edition. Chapter 1, page-49.

2. Mehdi G, Ansari HA, Sherwani RK, Rahman K, Akhtar N. Ovarian Steroid Cell Tumour: Correlation of Histopathology with Clinicopathologic features. Pathology Research International. Volume 2011, Article ID 987895, 5 pages.

3. Cooray SMA, Bulugahapitiya UDS, Praboda S. Steroid cell tumor not otherwise specified of bilateral ovaries: A rare cause of post-menopausal virilisation. Indian journal of endocrinology and metabolism. 2013:17(7):262-4.

4. Al-Farsi A, Al-Talib A. Steroid Cell Tumor. Sultan Qaboos Univ Med J. 2008;8(3):358-9.

5. Jiang W, Tao X, Fang F. Benign and malignant ovarian steroid cell tumors, not otherwise specified: case studies, comparison, and review of the literature. Journal of Ovarian Research. 2013;6:53.

Cite this article as: Banerjee $M$, Mukherjee $S$, Mahata M, Barui G. Outlandish presentation of a steroid cell tumor - distinct by its bilaterality and distant spread. Int J Reprod Contracept Obstet Gynecol 2016;5:1672-4. 